4 Sturzenegger M, Mattle HP, Rivoir AS, Baumgartner RW: Ultrasound findings in carotid artery dissection: analysis of 43 patients. Neurology 1995;45:691-698

5 Zuber J, Meary E, Meder JF, Mas JL: Magnetic resonance imaging and dynamic CT scan in cervical artery dissections. Stroke 1994;25:576581.

6 Bui LN, Brant-Zawadzki M, Verghese P, Gillan G: Magnetic resonance angiography of cervicocranial dissection. Stroke 1993;24:126-131.

7 Steinke W, Rautenberg W, Schwartz A, Hennerici M: Noninvasive monitoring of internal carotid artery dissection. Stroke 1994;25:998-1005.

8 Bartels E, Flügel KA: Evaluation of extracranial vertebral artery dissection with duplex color flow imaging. Stroke 1996;27:290-295.

9 Touboul PJ, Mas JL, Bousser MG, Laplane D: Duplex scanning in extracranial vertebral artery dissection. Stroke 1987;18:116-121.

10 Bartels E: Dissection of the vertebral arteries; in Bartels E (ed): ColorCoded Duplex Ultrasonography of the Cerebral Vessels/Atlas and Manual. Stuttgart, Schattauer, 1999, pp 125-127.

11 Bartels E: Dissection of the extracranial vertebral artery: clinical findings and early noninvasive diagnosis in 24 patients. J Neuroimag 2006;16: 24-33.

12 Saito K, Kimura K, Nagatsuka K, Nagano K, Minematsu K, Ueno S, Naritomi H: Vertebral artery occlusion in duplex color-coded ultrasonography. Stroke 2004;35:1068.

Eva Bartels, MD, Department of Clinical Neurophysiology Georg-August University Göttingen, Robert-Koch-Strasse 40 DE-37075 Göttingen (Germany)

Tel. +4989297 216, Fax +49892421 7799

E-Mail Bartels.Eva@t-online.de
Cerebrovasc Dis 2006;22:213-214

DOI: $10.1159 / 000093812$

\section{Fatal Embolic Myocardial Infarction after Systemic Thrombolysis for Stroke}

\author{
Wassilios Meissner ${ }^{a}$, Thomas Lempert ${ }^{a}$, \\ Sabine Saeuberlich-Knigge ${ }^{b}$, Wolfgang Bocksch ${ }^{c}$, \\ Ulrich-Frank Pape ${ }^{d}$
}

Departments of a Neurology, ${ }^{b}$ Nephrology and Intensive Care, ${ }^{\mathrm{C} C a r d i o l o g y}$, and ${ }^{\mathrm{d}}$ Hepatology, Gastroenterology, Endocrinology and Metabolism, Charité Campus VirchowKlinikum, Humboldt University Berlin, Berlin, Germany

\section{Introduction}

Systemic intravenous thrombolysis in stroke patients improves long-term clinical outcome when administered within $3 \mathrm{~h}$ following onset of the neurological deficit [1]. Therefore, systemic intravenous thrombolysis has been established as a first-line therapeutic strategy in patients admitted for stroke meeting specific criteria with cerebral hemorrhage being the main complication [1]. Since then, thrombolyis has proven to be cost-effective [2, 3], but only less than $4 \%$ of stroke patients currently benefit from thrombolytic treatment [4].

Although cardioembolism is the cause of $20-40 \%$ of all strokes $[5,6]$ and $26 \%$ of patients with an acute ischemic stroke or a transient ischemic attack have an intracardiac thrombus [7,
8], the risk for systemic embolism from a pre-existing intracardiac thrombus in stroke patients is unknown [9]. Here we report a patient who received systemic thrombolysis for stroke and who developed a finally fatal embolic MI from a presumably pre-existing atrial thrombus $2 \mathrm{~h}$ after initiation of systemic thrombolysis.

\section{Case Report}

A 62-year-old woman with a medical history of atrial fibrillation, arterial hypertension, diabetes mellitus and obesity was admitted to the emergency room for acute left brachiofacial hemiparesis and forced gaze deviation to the right. Initial laboratory evaluation showed unremarkable cardiac enzymes and coagulation parameters. A brain CT was normal except for a right hyperdense middle cerebral artery (MCA) pointing to occlusion of the vessel. The electrocardiogram (ECG) showed atrial fibrillation. Systemic thrombolysis with intravenous rt-PA (6.3 mg bolus, $56.7 \mathrm{mg}$ for $1 \mathrm{~h}$ ) was administered according to the guidelines of the NINDS rt-PA Stroke Study Group [1] starting two hours after the onset of the neurological symptoms. Two hours after rt-PA treatment the patient developed cardiogenic shock, required catecholamine therapy and was intubated for mechanical ventilation. ST segment elevations characteristic of anterior myocardial infarction appeared in ECG leads V2-V6 with reciprocal ST segment depression in the leads II, III and aVF. At this time creatine kinase (CK), creatine kinase-MB (CK$\mathrm{MB})$, and troponin $\mathrm{T}(\mathrm{TnT})$ levels were within normal limits. Immediate coronary angiography showed a complete occlusion of the left anterior descending coronary artery (LAD) and an abrupt occlusion of a small posterolateral branch of the left circumflex coronary artery. The residual coronary arterial tree was smooth without any lumen irregularities. Rescue percutaneous transluminal coronary angioplasty (PTCA) of the LAD was performed with a $25 \%$ residual diameter stenosis and a delayed distal run off of the contrast dye (grade II flow according to the Thrombolysis In Myocardial Infarction (TIMI) classification for coronary reperfusion) suggesting microcirculatory thromboembolism. Transesophageal echocardiography showed decreased left ventricular ejection fraction due to extended anterior, anteroseptal and apical akinesia. The left atrium was enlarged, while spontaneous echocontrast was documented and a large inhomogeneous mass $(1.8 \times 2.3 \mathrm{~cm})$ consistent with a thrombus adjacent to the lateral atrial wall was detected. Twelve hours after PTCA CK rose to 3,040 U/1 (CK-MB $196 \mathrm{U} / 1$ ) and TnT levels increased to $17.98 \mu \mathrm{g} / \mathrm{l}$. The patient showed hemodynamic deterioration and died within $24 \mathrm{~h}$ in global cardiac failure refractory to intensive medical therapy.

\section{Discussion}

This patient had a fatal embolic MI after systemic thrombolysis for stroke. Key clinical findings were a past medical history with atrial fibrillation, a previously unknown pre-existing thrombus in the left atrium, a right hyperdense MCA as a feature of large artery occlusion leading to acute ischemic stroke, and an abrupt occlusion of the LAD without atheromatous alterations on coronary angiography as the cause for acute MI. These changes strongly suggest a thromboembolic etiology of both the stroke and the MI most likely originating from the left atrial thrombus. Both thromboembolic events may be explained by spontaneous fragmentation of the inhomogeneous mass in the left atrium, but con- 
sidering the short interval between the initiation of intravenous thrombolysis and the manifestation of the MI, it seems likely that thrombolytic therapy triggered fragmentation of the pre-existing atrial thrombus with subsequent thromboembolic occlusion of the LAD and fatal MI.

Hitherto, coronary embolism has been observed in patients with atrial myxoma [10], aortic valve endocarditis [11], a preexisting left ventricular thrombus in dilated cardiomyopathy [12], atrial septal defects and cardiac surgery [13]. Moreover, a possible relationship between thrombolytic therapy and coronary embolism has been suggested [14], but there has been no such report in conjunction with systemic thrombolysis for stroke. However, thromboembolic complications have been observed in $1.5 \%$ of patients receiving systemic thrombolysis for acute MI who were believed to have a pre-existing clot [14] and in $12.6 \%$ of patients receiving systemic thrombolysis for prosthetic valve thrombosis [13]. However, a more detailed analysis of the Thrombolysis in Myocardial Infarction Phase II Pilot Study and Clinical Trial (TIMI-II) has shown that stroke occurs only in $0.22 \%$ of patients within $24 \mathrm{~h}$ after the beginning of intravenous thrombolysis suggesting that the risk of clot fragmentation with subsequent cardioembolic stroke might be small in relation to rt-PA treatment for MI [15]. Since $26 \%$ of patients with an acute ischemic stroke or a transient ischemic attack have an intracardiac thrombus [7, 8], the risk for embolic MI or systemic embolism from a pre-existing intracardiac thrombus seems also to be small in stroke patients.

In conclusion, since embolic MI mainly originates from cardiac thromboembolism, a pre-existing cardiac thrombus may carry an increased risk for embolic MI. The presented observation further suggests that embolism from pre-existing cardiac thrombi has to be considered as a potential adverse event of intravenous rt-PA administration in stroke patients. More attention will be necessary to determine the level of importance of this observation in clinical practice.

\section{Acknowledgements}

The authors are grateful to L.R. Caplan (Boston, Mass., USA) and J.-M. Orgogozo (Bordeaux, France) for helpful discussion and critical reading of the manuscript.

\section{References}

1 The NINDS rt-PA Stroke Study Group: Tissue plasminogen activator for acute ischemic stroke. N Engl J Med 1995;333:1581-1587.

2 Mar J, Begiristain JM, Arrazola A: Cost-effectiveness analysis of thrombolytic treatment for stroke. Cerebrovasc Dis 2005;20:193-200.

3 Fagan SC, Morgenstern LB, Petitta A, Ward RE, Tilley BC, Marler JR, Levine SR, Broderick JP, Kwiatkowski TG, Frankel M, Brott TG, Walker MD: Cost-effectiveness of tissue plasminogen activator for acute ischemic stroke. NINDS rt-PA Stroke Study Group. Neurology 1998;50:883-890.

4 Davalos A: Thrombolysis in acute ischemic stroke: successes, failures, and new hopes. Cerebrovasc Dis 2005;20(suppl 2):135-139.

5 Bogousslavsky J, Van Melle G, Regli F: The Lausanne Stroke Registry: analysis of 1,000 consecutive patients with first stroke. Stroke 1988;19: 1083-1092.

6 Olsen TS, Skriver EB, Herning M: Cause of cerebral infarction in the carotid territory. Its relation to the size and the location of the infarct and to the underlying vascular lesion. Stroke 1985;16:459-466.

7 Sen S, Laowatana S, Lima J, Oppenheimer SM: Risk factors for intracardiac thrombus in patients with recent ischaemic cerebrovascular events. $\mathrm{J}$ Neurol Neurosurg Psychiatry 2004; 75:1421-1425.

8 MacKenzie JM: Are all cardio-embolic strokes embolic? An autopsy study of 100 consecutive acute ischaemic strokes. Cerebrovasc Dis 2000;10: 289-292.

9 Caplan LR: Of birds and nests and brain emboli. Rev Neurol (Paris) 1991; 147:265-273.

10 Abascal VM, Kasznica J, Aldea G, Davidoff R: Left atrial myxoma and acute myocardial infarction: a dangerous duo in the thrombolytic agent era. Chest 1996;109:1106-1108.

11 Perera R, Noack S, Dong W: Acute myocardial infarction due to septic coronary embolism. N Engl J Med 2000;342:977-978.

12 Lanza GM, Berman BJ, Tanuchi M: Multifocal coronary thromboembolism from a left ventricular thrombus. N Engl J Med 1999;341:10831084.

13 Koller PT, Arom KV: Thrombolytic therapy of left-sided prosthetic valve thrombosis. Chest 1995;108:1683-1689.

14 Stafford PJ, Strachan CJ, Vincent R, Chamberlain DA: Multiple microemboli after disintegration of clot during thrombolysis for acute myocardial infarction. BMJ 1989;299:1310-1312.

15 Sloan MA, Price TR, Terrin ML, Forman S, Gore JM, Chaitman BR, Hodges M, Mueller H, Rogers WJ, Knatterud GL, Braunwald E: Ischemic cerebral infarction after rt-PA and heparin therapy for acute myocardial infarction: the TIMI-II pilot and randomized clinical trial combined experience. Stroke 1997;28:1107-1114.

Dr. Wassilios Meissner, Department of Neurology, CHU Pellegrin Place Amélie Raba-Léon, FR-33076 Bordeaux cedex (France) Tel. +33556795520, Fax +33556798702

E-Mail wassilios.meissner@chu-bordeaux.fr 